\title{
Fabrication and Characterization of Superhydrophobic Graphene/Titanium Dioxide Nanoparticles Composite
}

\author{
Xun Hui Wu ${ }^{1, *(D)}$ and Yoon Yee Then ${ }^{2, *(D)}$ \\ 1 School of Postgraduate Studies, International Medical University, Kuala Lumpur 57000, Malaysia \\ 2 Department of Pharmaceutical Chemistry, School of Pharmacy, International Medical University, \\ Kuala Lumpur 57000, Malaysia \\ * Correspondence: xunhui.wu@outlook.com (X.H.W.); thenyoonyee@imu.edu.my (Y.Y.T.)
}

Citation: Wu, X.H.; Then, Y.Y. Fabrication and Characterization of Superhydrophobic Graphene/Titanium Dioxide Nanoparticles Composite. Polymers 2022, 14, 122. https:// doi.org/10.3390/polym14010122

Academic Editor: Constantinos Tsitsilianis

Received: 16 November 2021 Accepted: 3 December 2021 Published: 30 December 2021

Publisher's Note: MDPI stays neutral with regard to jurisdictional claims in published maps and institutional affiliations.

Copyright: (C) 2021 by the authors. Licensee MDPI, Basel, Switzerland. This article is an open access article distributed under the terms and conditions of the Creative Commons Attribution (CC BY) license (https:/ / creativecommons.org/licenses/by/ $4.0 /)$.

\begin{abstract}
Materials with superhydrophobic surfaces have received vast attention in various industries due to their valuable properties, such as their self-cleaning and antifouling effects. These promising superhydrophobic properties are taken into high priority, particularly for medical devices and applications. The development of an ideal superhydrophobic surface is a challenging task and is constantly progressing. Various strategies have been introduced; however, a minority of them are costeffective. This work presents a facile fabrication of the superhydrophobic surface by using graphene and titanium dioxide $\left(\mathrm{TiO}_{2}\right)$ nanoparticles. The graphene and $\mathrm{TiO}_{2}$ hybrid nanoparticles are dipcoated on a biodegradable thermoplastic poly(lactic acid) (PLA) substrate. The thermoplastic PLA is approved by the Food and Drug Administration (FDA), and is widely utilized in medical devices. The graphene $/ \mathrm{TiO}_{2}$ coating is substantiated to transform the hydrophilic PLA film into superhydrophobic biomaterials that can help to reduce hazardous medical-device complications. The surface wettability of the graphene $/ \mathrm{TiO}_{2}$ nanoparticle-coated PLA surface was evaluated by measuring the apparent water contact angle. The surface chemical composition and surface morphology were analyzed via Fourier-transform infrared spectroscopy (FTIR) and scanning electron microscopy (SEM). The graphene $/ \mathrm{TiO}_{2}$-coated PLA film achieved superhydrophobic properties by demonstrating a water contact angle greater than $150^{\circ}$. The water contact angle of the graphene $/ \mathrm{TiO}_{2}$ coating increased along with the concentration of the nanoparticles and the ratio of $\mathrm{TiO}_{2}$ to graphene. Moreover, the graphene $/ \mathrm{TiO}_{2}$ coating exhibited excellent durability, whereby the contact angle of the coated surface remained unchanged after water immersion for $24 \mathrm{~h}$. The duration of the effectiveness of the superhydrophobic coating suggests its suitability for medical devices, for which a short duration of administration is involved. This study reports an easy-to-replicate and cost-effective method for fabricating superhydrophobic graphene/ $\mathrm{TiO}_{2}$-coated surfaces, which additionally substantiates a potential solution for the manufacturing of biomaterials in the future.
\end{abstract}

Keywords: superhydrophobic; graphene; titanium dioxide; dip coating; contact angle

\section{Introduction}

Superhydrophobic biomaterials have been commonly employed in various applications due to their non-wettability. The superhydrophobic effect of these materials is generally indicated by a high contact angle $\left(>150^{\circ}\right)[1,2]$. The fundamental principles of superhydrophobic properties take into account the low surface energy and high surface roughness [3-5]. The Cassie-Baxter and Wenzel models describe the superhydrophobic wetting state attributed to the structured or patterned surface in the micro/nanoscale, which reduces direct contact between the liquid and the solid surface [6]. This surface roughness leads to water repellence, and consequently, endows the self-cleaning effect. The dirt is carried away by water as it rolls off the superhydrophobic surface [7]. In the practical situation, a transition between the Cassie-Baxter regime and the Wenzel wetting regime may occur. Nonetheless, both wetting states elucidate the wettability of superhydrophobic 
surfaces. In addition, the superhydrophobic surface induces an antibacterial effect by reducing the adhesion point of the microbes onto the surface. Currently, this antifouling effect is said to be an important factor for most instruments, including medical devices $[1,8]$. The antifouling coating can act as a fouling-resistant, fouling-release, or fouling-degrading agent [9]. Fouling-resistant and fouling-release agents prevent adhesion and weaken the bonding between the substance and the surface, whereas fouling-degrading agents destroy the adsorbed substance via an oxidizing agent or bactericidal functionalities $[9,10]$. In light of these mechanisms, the superhydrophobic surface is suggested to contribute as a foulingresistant and fouling-release agent. These properties, attributed to the superhydrophobic surface, show a promising impact on the applications of medical devices.

Developments of functional superhydrophobic surfaces are mostly inspired by nature, for example, by the hierarchical structure of the lotus leaf, which provides the infamous lotus leaf effect, as well as the water-repellent surfaces of insects [11-13]. Various approaches to fabricating practical and functional superhydrophobic surfaces have been reviewed $[9,14-16]$. However, most of the methods are time-consuming, strenuous, and costly. These factors tend to result in low producibility. Herein, we discuss a facile, cost-effective, time-saving, and replicable strategy for fabricating superhydrophobic surfaces, namely, by dip-coating graphene and titanium dioxide $\left(\mathrm{TiO}_{2}\right)$ nanoparticles onto a poly(lactic acid) (PLA) substrate. This method is substantiated to be employed in the large-scale production of superhydrophobic biomaterials, particularly targeting medical devices.

Graphene and $\mathrm{TiO}_{2}$ are introduced as the coating materials due to their tendency to improve hydrophobicity, and their high corrosion resistance and low toxicity [17-21]. The combination of these two materials provides a synergistic effect, lowering surface wettability via an enhancement of surface roughness. In addition to the improved selfcleaning effect, graphene $/ \mathrm{TiO}_{2}$ nanocomposite materials exhibit enhanced antibacterial activities by suppressing the growth of both gram-negative and gram-positive bacteria via photocatalytic activity and suppressing the generation of reactive oxygen species [22-26]. Additionally, PLA was chosen as the substrate for coating because of its excellent mechanical properties and biodegradability, and its non-toxicity is suited to various medical applications [27]. The Food and Drug Administration (FDA) has approved the usage of PLA in, for example, surgical devices, where direct contact with biological fluids is present [28]. Previous studies substantiated that reinforcing PLA with a low concentration of nanoparticles further enhances the structural and functional properties of PLA [29,30].

The superhydrophobic graphene $/ \mathrm{TiO}_{2}$ coating that was fabricated in this work aims to target applications, particularly medical devices, that require self-cleaning properties. The rough topography of the graphene $/ \mathrm{TiO}_{2}$ surface provides protrusions that trap an adequate amount of air layers within the surface structure and promote resistance to bacterial adhesion. This mechanism induces the inhibition of biofilm formation [31,32]. In addition, surfaces modified with graphene and $\mathrm{TiO}_{2}$ have shown superior bactericidal effects and antifouling abilities [33-37]. The low surface energy of the modified superhydrophobic surface is substantiated to lower the cell-surface interaction, as well as the solid-liquid interaction [38,39]. The superhydrophobic surface lubricates the liquid flow by introducing an effective slip boundary, thereby generating minimum shear stress [40]. The present study offers a simple strategy for fabricating a superhydrophobic graphene/ $\mathrm{TiO}_{2}$ coating on PLA film via the dip-coating method. Herein, we propose that the artificial superhydrophobic surface fabricated via a simple step is appropriate for imparting into medical devices, for which self-cleaning and antimicrobial properties are desirable.

\section{Materials and Methods}

\subsection{Materials}

Graphene nanoplatelets (oxidized, composition of $>95 \%$ carbon and $>1 \%$ oxygen, lateral dimension 2-3 $\mu \mathrm{m}$, BET surface area $\left.110 \mathrm{~m}^{2} / \mathrm{g}\right)$ and titanium dioxide $\left(\mathrm{TiO}_{2},<25 \mathrm{~nm}\right.$ particle size, $99.7 \%$ trace metal basis) were obtained from Sigma-Aldrich, MO, USA. Polydimethylsiloxane (PDMS) prepolymers and curing agents were purchased from the 
Dow Corning Corporation, Lansing, MI, USA. Poly(lactic acid) (3052 D) was purchased from Natureworks LLC, Saint Paul, MN, USA. Chemicals, including n-hexane $\left(\mathrm{C}_{6} \mathrm{H}_{14}, 96 \%\right.$ purity) and chloroform $\left(\mathrm{CHCl}_{3}\right)$, were obtained from Merck, Darmstadt, Germany, and were used as received.

\subsection{Preparation of Thermoplastic Poly(Lactic Acid) Substrate}

The thermoplastic poly(lactic acid) (PLA) film was prepared using PLA grade $3052 \mathrm{D}$. PLA pellets of 5 weight $\%$ were used to produce a transparent and resilient PLA film. The PLA pellets were dissolved in $30 \mathrm{~mL}$ of chloroform by stirring for $1 \mathrm{~h}$ at $50{ }^{\circ} \mathrm{C}$. The clear PLA solution was cast onto a glass petri dish and dried at room temperature for $24 \mathrm{~h}$.

\subsection{Preparation of Graphene/Titanium Dioxide-Coated PLA Film}

The graphene $/ \mathrm{TiO}_{2}$ coating solution was prepared with different concentrations of nanoparticles $(0.1,0.3,0.5,0.7$, and $0.9 \% w / v)$ in $30 \mathrm{~mL}$ of hexane. Each concentration of the coating solution contained graphene nanoplatelets and $\mathrm{TiO}_{2}$ nanoparticles with ratios of 10:0, 9:1, 7:3, 5:5, 3:7, 1:9, and 0:10. Prior to mixing, $0.3 \mathrm{~g}$ of PDMS (10:1 ratio of base to curing agent) was added into the solution. The suspension was then stirred for $10 \mathrm{~min}$, followed by ultrasonication for $15 \mathrm{~min}$. Poly(lactic acid) film $(2 \mathrm{~cm} \times 4.5 \mathrm{~cm})$ was dip-coated with the graphene $/ \mathrm{TiO}_{2}$ solution, at a withdrawal speed of $2 \mathrm{~mm} / \mathrm{s}$, and dried at ambient temperature. The dip-coating process was repeated 3 times. The final product was cured in the oven at $50^{\circ} \mathrm{C}$ for $1 \mathrm{~h}$.

\subsection{Contact Angle Measurement}

The static water contact angles on the surfaces were measured by using a goniometer (Ossila L2006A1, Ossila Ltd., Sheffield, UK). A droplet of distilled water with a volume of $10 \mu \mathrm{L}$ was applied onto the surface of the films. The contact angle of the water droplet was measured immediately after droplet stability. The sessile water contact angles on both sides of the droplet were measured and the average value was recorded. The test was performed in triplicate.

\subsection{Chemical Interaction and Morphological Evaluation}

The surface chemical compositions were determined by using Fourier-transform infrared spectroscopy (FTIR, IRTracer-100, Shimadzu Corporation, Kyoto, Japan). The FTIR spectra were collected over a spectrum range of $400-4000 \mathrm{~cm}^{-1}$ with a resolution of $4 \mathrm{~cm}^{-1}$, and analyzed with LabSolutions IR Software (version 2.2). The surface morphology was assessed by using the scanning electron microscope (SEM, TM3000, Hitachi HighTechnologies Corporation, Tokyo, Japan).

\subsection{Durability Test}

A water immersion test was used to evaluate the resistance of the graphene $/ \mathrm{TiO}_{2}-$ coated film to water exposure over a prolonged time. The graphene $/ \mathrm{TiO}_{2}$-coated film was immersed in distilled water at room temperature for $24 \mathrm{~h}$. The contact angle measurements were performed immediately after the samples were dried.

\section{Results}

\subsection{Contact Angle Evaluation of Graphene/TiO $\mathrm{O}_{2}$ Coating}

The superhydrophobic graphene/ $\mathrm{TiO}_{2}$ coating on PLA film was successfully fabricated via dip coating. The graphene $/ \mathrm{TiO}_{2}$ nanocomposites coating achieved superhydrophobic properties, as shown in Figure 1. The low wettability of the superhydrophobic graphene $/ \mathrm{TiO}_{2}$ is illustrated via the high apparent water contact angle. The hydrophilic PLA film, with a contact angle of $77 \pm 5^{\circ}$, transformed into a superhydrophobic surface (contact angle of $>150^{\circ}$ ) upon the application of the graphene/titanium dioxide coating. 


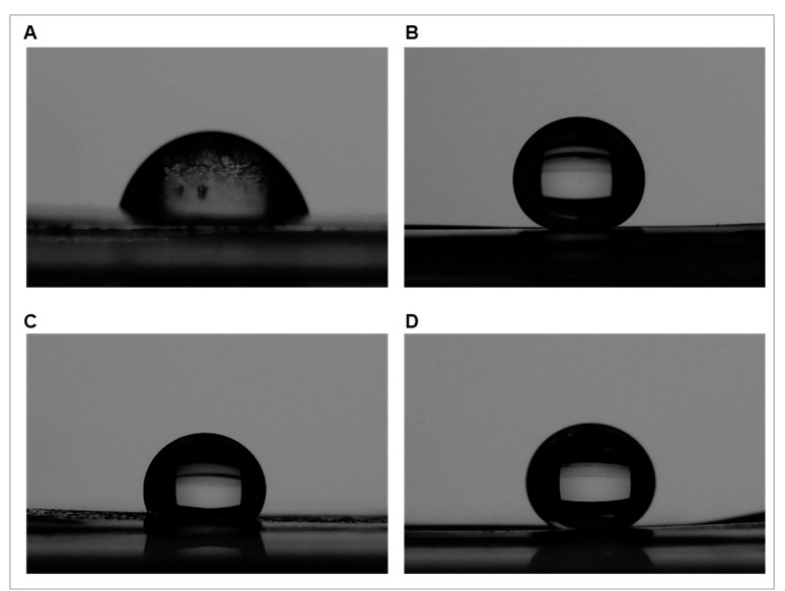

Figure 1. The water contact angle of poly(lactic acid) film (A) without the graphene $/ \mathrm{TiO}_{2}$ coating, (B) with the graphene $/ \mathrm{TiO}_{2}$ coating, (C) with the graphene coating, and (D) with the $\mathrm{TiO}_{2}$ coating on the surface.

This phenomenon suggests that the enhancement of the surface roughness by the graphene and $\mathrm{TiO}_{2}$ nanoparticles concomitantly improves the non-wettability of the surface. This result is in concordance with the statement mentioning that superhydrophobic properties are influenced by surface roughness and the chemical composition of the surface. In addition to the low surface energy, the graphene and $\mathrm{TiO}_{2}$ nanoparticles provide the hierarchical structure to the surface of PLA film and thus endow the modified surface with low wettability. The surface roughness, attributed to the micro/nano structures on the graphene $/ \mathrm{TiO}_{2}$ surface, entrapped a sufficient air layer on the surface. Hence, high water contact angles are observed, due to the reduction of the contact point between the water droplet and the coated surface.

The contact angle of the PLA surface increased as the concentration of the graphene and $\mathrm{TiO}_{2}$ coating on the surface increased from $0.1 \%$ to $0.5 \%$. Thereafter, the contact angle of the graphene $/ \mathrm{TiO}_{2}$-coated PLA surface slightly decreased when the concentration rose to $0.7 \%$, followed by a surge at $0.9 \%$. In other words, the graphene $/ \mathrm{TiO}_{2}$ coating alters the surface structure of the PLA film and transforms the surface-wetting properties from hydrophilic to hydrophobic, and later to superhydrophobic, as the concentration of graphene/ $\mathrm{TiO}_{2}$ nanocomposites increases (Figure 2). However, the graphene/ $\mathrm{TiO}_{2}$ coatings exhibited a higher contact angle compared to graphene and $\mathrm{TiO}_{2}$ alone. This result substantiates the synergistic effect, promoting superhydrophobic properties induced by the combination of graphene and $\mathrm{TiO}_{2}$. It is suggested that the $\mathrm{TiO}_{2}$ nanoparticles covered up the empty spaces between the graphene nanoparticles, or vice versa. The mixture of these nanoparticles conferred an appropriate distance or interspacing between them. Therefore, the surface roughness established by these protrusions limits the anchoring point for the water onto the surface. In addition to acting as an adhesive agent between the nanoparticle coating and the PLA surface, the presence of PDMS lowered the surface energy of the modified surface further, and thus lowered the wettability of the graphene $/ \mathrm{TiO}_{2}$-coated surface. In addition to lowering the surface energy, PDMS crosslinking helps to improve the elasticity and durability of the coated film [36].

It is noteworthy that, for the $0.5 \% w / v$ graphene $/ \mathrm{TiO}_{2}$ coating, the water contact angle of the coated surface increased as the graphene to $\mathrm{TiO}_{2}$ ratio decreased. The highest contact angle, $164.21 \pm 1^{\circ}$, was achieved with a graphene to $\mathrm{TiO}_{2}$ ratio of 1:9. The introduction of $\mathrm{TiO}_{2}$ in the coating provided an enhancement to the surface roughness by creating a rough texture on the surface. As the amount of $\mathrm{TiO}_{2}$ increased, the nanoparticles further increased the surface roughness by reducing the chemical inhomogeneity while maintaining the surface structure. Hence, this condition results in greater hydrophobicity [41]. However, as the ratio of graphene to $\mathrm{TiO}_{2}$ nanoparticles increased, the graphene nanoparticles covered the porous texture of the surface, an effect accredited to the $\mathrm{TiO}_{2}$ nanoparticles. The high 
amount of graphene nanoparticles thereby created an uneven surface with large spacings and thus lowered the contact angle [25]. The surface roughness increased when the $\mathrm{TiO}_{2}$ to graphene ratio was high, and vice versa. For the $0.7 \% w / v$ graphene $/ \mathrm{TiO}_{2}$ coating, the water contact angle was not influenced by the graphene to $\mathrm{TiO}_{2}$ ratio, whereas for the $0.9 \%$ $w / v$ graphene $/ \mathrm{TiO}_{2}$ coating, the highest contact angle $\left(161.56 \pm 1^{\circ}\right)$ was obtained when the ratio of graphene to $\mathrm{TiO}_{2}$ was equal. In concordance with previous studies [23,25], the introduction of $\mathrm{TiO}_{2}$ provided surface roughness to the coated surface. The addition of graphene further enhanced the textured surface by establishing the hierarchical nanostructure on the superhydrophobic surface. Therefore, both graphene and $\mathrm{TiO}_{2}$ exert a synergistic effect to produce a surface with superhydrophobic properties.

As the concentration of the graphene $/ \mathrm{TiO}_{2}$ solution increased, the contact angle of the graphene/titanium dioxide-coated PLA surface increased (Figure 3). Interestingly, there was a surge in the contact angle when the concentration of graphene $/ \mathrm{TiO}_{2}$ nanoparticles increased from $0.3 \% w / v$ to $0.5 \% w / v$. This drastic increment in the contact angle was attributed to the increased amount of graphene and $\mathrm{TiO}_{2}$ nanoparticles; therefore, it endows sufficient surface roughness, allowing for the remodeling of the graphene/ $\mathrm{TiO}_{2}$-coated PLA surface from a hydrophobic to a superhydrophobic surface.
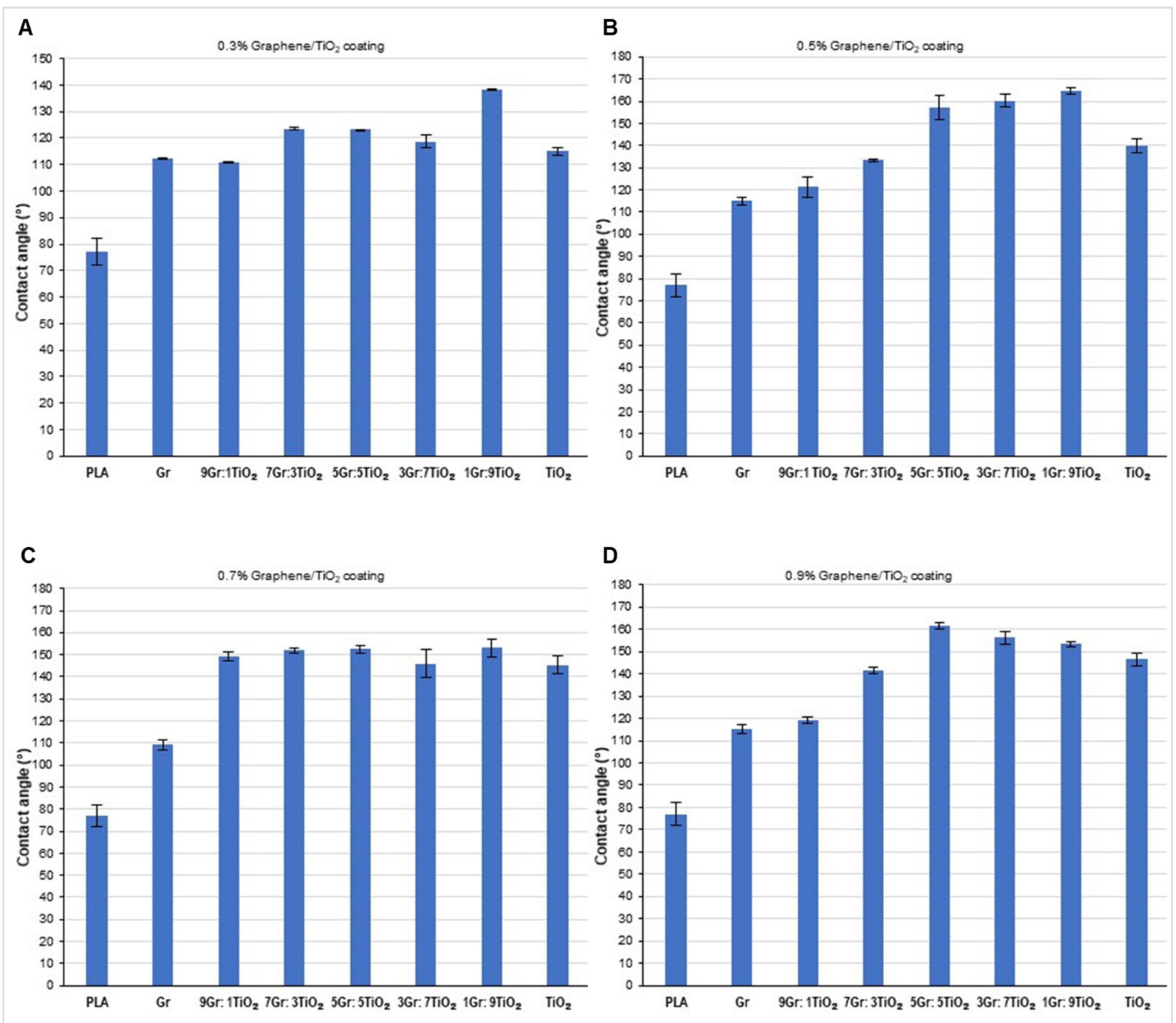

Figure 2. Water contact angle of the PLA film coated with (A) $0.3 \% w / v$ graphene $/ \mathrm{TiO}_{2},(\mathbf{B}) 0.5 \%$ $w / v$ graphene $/ \mathrm{TiO}_{2},(\mathbf{C}) 0.7 \% w / v$ graphene $/ \mathrm{TiO}_{2}$, and (D) $0.9 \% w / v$ graphene $/ \mathrm{TiO}_{2}$. PLA without coating acts as a control; $\mathrm{Gr}$ represents graphene and $\mathrm{TiO}_{2}$ represents titanium dioxide. 


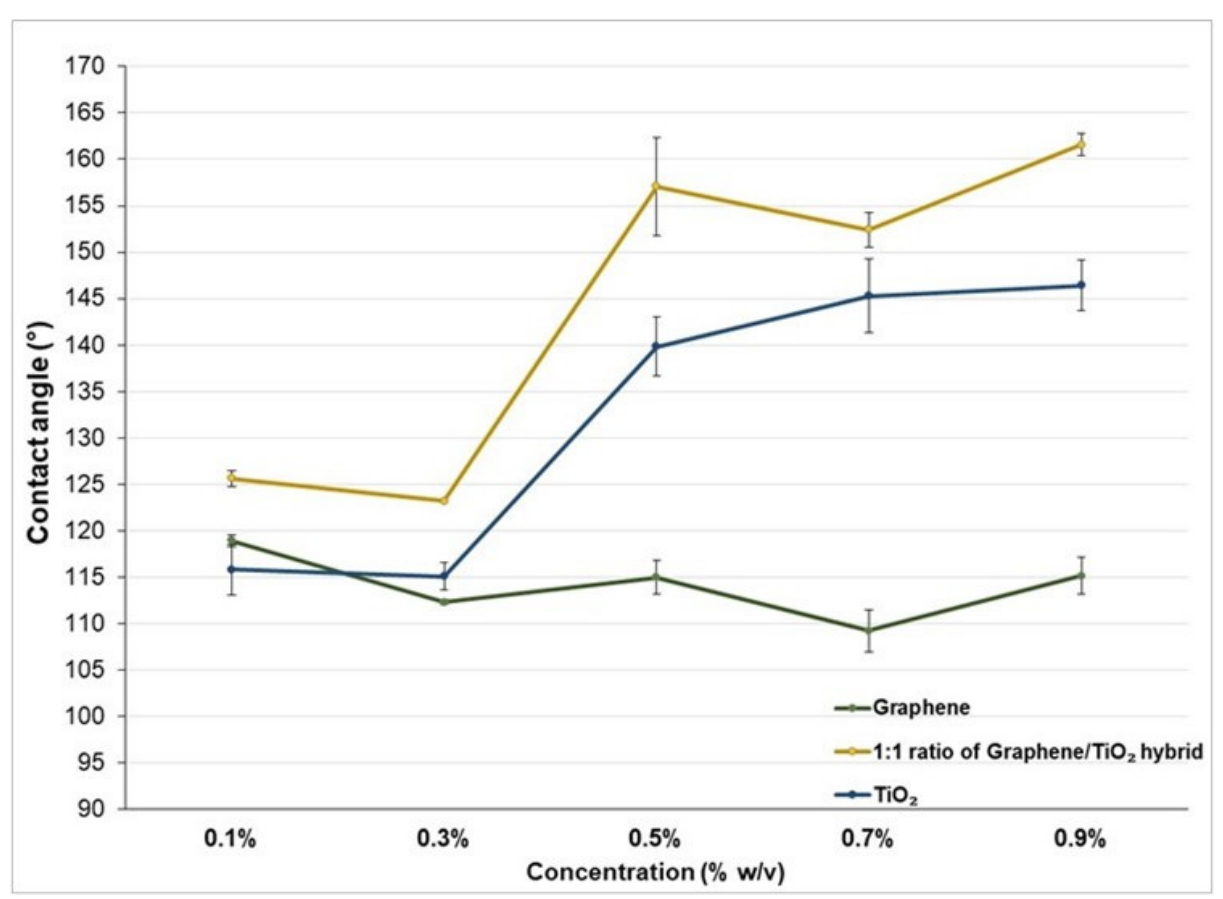

Figure 3. Comparison between the apparent contact angle of $0.1 \% w / v, 0.3 \% w / v, 0.5 \% w / v, 0.7 \%$ $w / v$, and $0.9 \% w / v$ of the graphene $/ \mathrm{TiO}_{2}$ coating.

The hierarchically structured surface attributed to the graphene and $\mathrm{TiO}_{2}$ nanoparticles allows for the entrapment of air within the contact boundary, thus reducing the contact point of the water droplet on the graphene $/ \mathrm{TiO}_{2}$-coated surface. The porosity factor, or void ratio, was determined to estimate the volume of air entrapped by the roughened surface. The porosity factor can be calculated using the Cassie-Baxter equation [6], cos $\theta_{\mathrm{c}}=f_{s}(\cos \theta+1)-1$, where $f_{s}$ indicates the total area of the solid-liquid interface and $\theta_{\mathrm{c}}$ represents the contact angle of the coated PLA surface, whereas $\theta$ represents the contact angle of the smooth PLA surface. By substituting $77^{\circ}$, which is the contact angle of the smooth unmodified PLA film, and the contact angles of the respective coated surface into the equation, the result for $f_{s}$ can be determined (Table 1). The result shows that the $f_{s}$ value for the superhydrophobic surface is less than 0.1, which is in agreement with the previous studies reported by Karapanagiotis et al. and Basu et al. [42,43] The surface roughness attributed to the graphene and $\mathrm{TiO}_{2}$ allowed for a sufficient amount of air entrapment on the surface, thereby lowering the wettability and endowing the graphene $/ \mathrm{TiO}_{2}$-coated surface with superhydrophobic properties.

\subsection{Surface Chemical Composition and Surface Morphology Evaluation}

The chemical functional groups of the graphene $/ \mathrm{TiO}_{2}$ coating are characterized via FTIR, as illustrated in Figure 4. The peaks between $3000 \mathrm{~cm}^{-1}$ to $3600 \mathrm{~cm}^{-1}$ represent the $\mathrm{O}-\mathrm{H}$ stretching. The peaks around 1000 to $1200 \mathrm{~cm}^{-1}$ represent the $\mathrm{C}-\mathrm{O}-\mathrm{C}$ stretching of PLA. The peaks of ester are depicted at $1083 \mathrm{~cm}^{-1}$, belonging to the $\mathrm{C}-\mathrm{O}-\mathrm{O}$ stretching vibration, and circa $3000 \mathrm{~cm}^{-1}$, which belongs to the $\mathrm{CH}_{3}$ stretching band. Moreover, the asymmetric and symmetric $\mathrm{C}-\mathrm{H}$ deformations in $\mathrm{CH}_{3}$ bending are depicted by the peaks at $1454 \mathrm{~cm}^{-1}$ and $1365 \mathrm{~cm}^{-1}$. The carbonyl $\mathrm{C}=\mathrm{O}$ stretching is depicted as the peak at $1751 \mathrm{~cm}^{-1}$. The bands between $1630 \mathrm{~cm}^{-1}$ to $1800 \mathrm{~cm}^{-1}$ represent the $\mathrm{C}=\mathrm{C}$ bond [44-47]. The presence of $\mathrm{TiO}_{2}$ produces an intensified peak at $1454 \mathrm{~cm}^{-1}$. The Ti-O stretching band can also be observed at $890 \mathrm{~cm}^{-1}$ and $750 \mathrm{~cm}^{-1}[18,48]$ The peaks for PDMS are observed at $860 \mathrm{~cm}^{-1}$ and $1253 \mathrm{~cm}^{-1}$, attributed to the in-plane and out-of-plane bending of the $\mathrm{Si}-\mathrm{CH}_{3}$ [25]. The peaks between $2900 \mathrm{~cm}^{-1}$ and $3000 \mathrm{~cm}^{-1}$ represent $\mathrm{C}-\mathrm{H}$ stretching, while the peaks between 1000 to $1400 \mathrm{~cm}^{-1}$ represent $\mathrm{C}-\mathrm{O}$ stretching. The peaks around 
$1000 \mathrm{~cm}^{-1}$ to $1130 \mathrm{~cm}^{-1}$, which represent the $\mathrm{Si}-\mathrm{O}-\mathrm{Si}$ bands of PDMS, is suggested to be overlapped with the $\mathrm{C}-\mathrm{O}$-stretching bands.

Table 1. The total area of the solid-liquid interface of the graphene/ $\mathrm{TiO}_{2}$-coated PLA film with the concentration of $0.1 \%$ to $0.9 \%$ and different graphene to $\mathrm{TiO}_{2}$ ratios. $\mathrm{Gr}$ and $\mathrm{TiO}_{2}$ represent the abbreviation of graphene and titanium dioxide, respectively.

\begin{tabular}{lccccccc}
\hline & \multicolumn{7}{c}{ Total Area of Solid-Liquid Interface, $f_{s}$} \\
\cline { 2 - 7 } & Gr Only & $\begin{array}{c}\mathrm{Gr} / \mathbf{T i O}_{2} \\
\mathbf{( 9 : 1 )}\end{array}$ & $\begin{array}{c}\mathrm{Gr} / \mathrm{TiO}_{2} \\
\mathbf{( 7 : 3 )}\end{array}$ & $\begin{array}{c}\mathrm{Gr} / \mathrm{TiO}_{2} \\
\mathbf{( 1 : 1 )}\end{array}$ & $\begin{array}{c}\mathrm{Gr} / \mathbf{T i O}_{2} \\
\mathbf{( 3 : 7 )}\end{array}$ & $\begin{array}{c}\mathrm{Gr} / \mathrm{TiO}_{2} \\
\mathbf{( 1 : 9 )}\end{array}$ & $\begin{array}{c}\mathbf{T i O}_{2} \\
\mathbf{O n n l y}^{\prime}\end{array}$ \\
\hline $\begin{array}{l}0.1 \% w / v \\
\mathrm{Gr} / \mathrm{TiO}_{2}\end{array}$ & 0.42 & 0.38 & 0.38 & 0.34 & 0.40 & 0.39 & 0.46 \\
\hline $\begin{array}{l}0.3 \% w / v \\
\mathrm{Gr} / \mathrm{TiO}_{2}\end{array}$ & 0.51 & 0.53 & 0.36 & 0.37 & 0.42 & 0.21 & 0.47 \\
\hline $\begin{array}{l}0.5 \% w / v \\
\mathrm{Gr} / \mathrm{TiO}_{2}\end{array}$ & 0.47 & 0.39 & 0.26 & 0.06 & 0.05 & 0.03 & 0.19 \\
\hline $\begin{array}{l}0.7 \% w / v \\
\mathrm{Gr} / \mathrm{TiO}_{2}\end{array}$ & 0.55 & 0.11 & 0.10 & 0.09 & 0.14 & 0.09 & 0.15 \\
\hline $\begin{array}{l}0.9 \% w / v \\
\mathrm{Gr} / \mathrm{TiO}_{2}\end{array}$ & 0.47 & 0.42 & 0.18 & 0.04 & 0.07 & 0.09 & 0.14 \\
\hline
\end{tabular}

The surface morphologies of the non-coated PLA film and the graphene $/ \mathrm{TiO}_{2}$-coated film are illustrated in Figures 4 and 5. Undoubtedly, PLA exhibits a smooth surface. The surface morphology of the graphene/ $\mathrm{TiO}_{2}$-coated surface shows a homogenous distribution of graphene and $\mathrm{TiO}_{2}$ nanoparticles. The uniform coverage of graphene and $\mathrm{TiO}_{2}$ nanoparticles provides a roughness to the surface, which is accountable for the low surface wettability. The graphene nanoplatelets are irregular in shape, whereas the $\mathrm{TiO}_{2}$ nanoparticles appear to have a nanoscopic particle size of less than $50 \mu \mathrm{m}$. The hierarchical structure on the coated surface is attributed to the graphene $/ \mathrm{TiO}_{2}$ nanoparticles acting as protrusions. The interspacing between the protrusions allows for an adequate amount of air pockets to be entrapped on the surface. As depicted in the 3D images in Figure 5, the surface roughness can be estimated via the presence of protrusions on the coated surface. The graphene $/ \mathrm{TiO}_{2}$ coating provides protrusions with different heights and interspacing, which help to minimize the contact point of liquid on the surface. This result correlates with the aforementioned porosity factor in Table 1 . The porosity factor of the surface or the total surface area of the solid-liquid interface decreases drastically upon the introduction of graphene and $\mathrm{TiO}_{2}$ nanoparticles. The graphene $/ \mathrm{TiO}_{2}$ hybrid nanocomposite confers a higher degree of surface roughness, therefore manifesting a greater reduction in the total surface area of the solid-liquid interface. The mixture of graphene and $\mathrm{TiO}_{2}$ nanoparticles offers an optimal surface roughness, which allows for a sufficient amount of air-layer entrapment, thus furnishing the coated surface with superhydrophobic properties. We suggest that the Cassie-Baxter regime be used for this scenario. The minimal solid-liquid interface, consequently, results in the high-water contact angle, and hence, the superhydrophobic properties. 


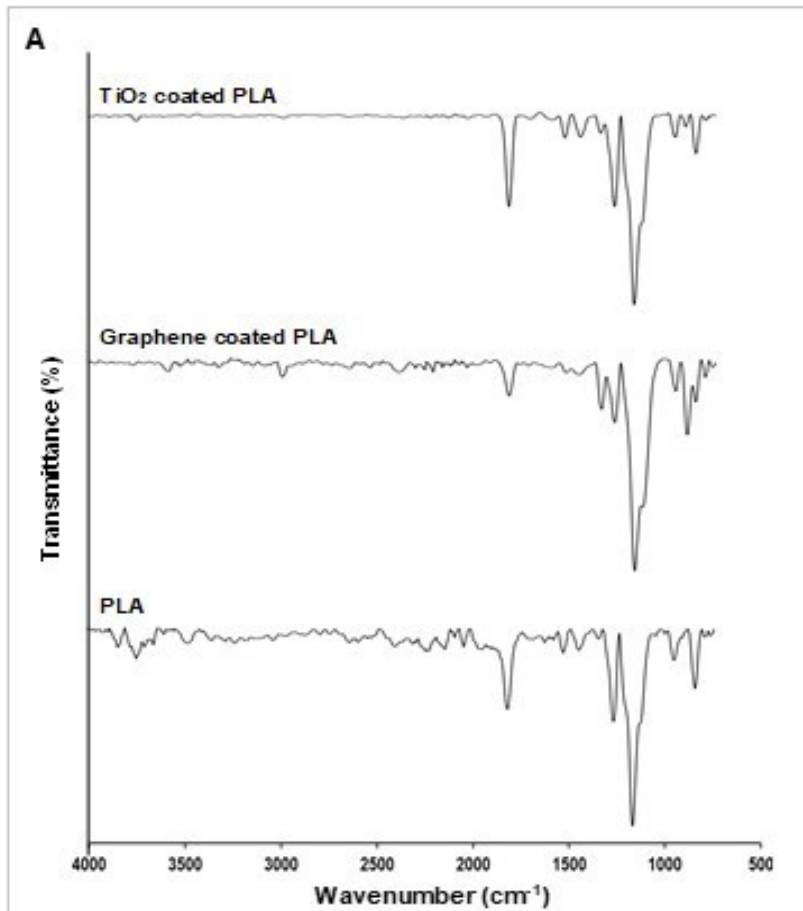

C

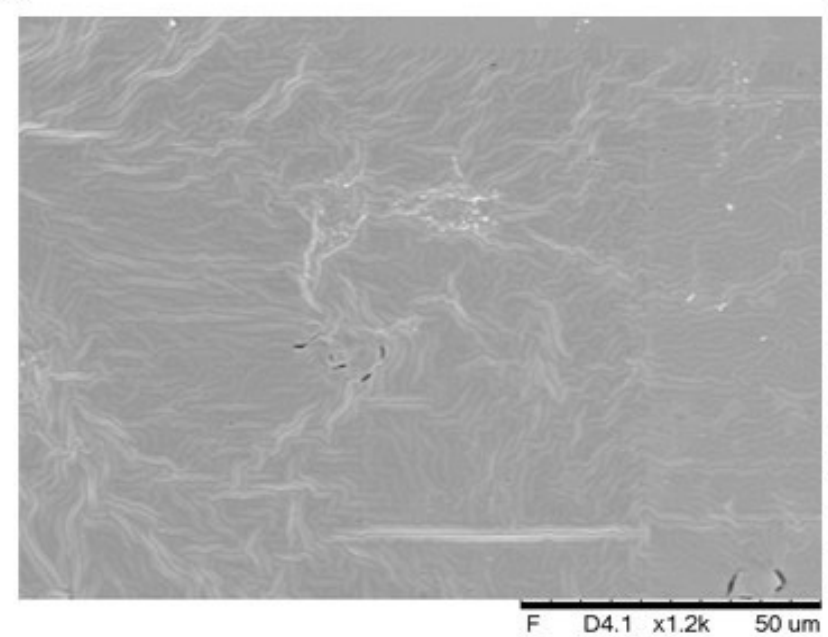

$\mathbf{B}$

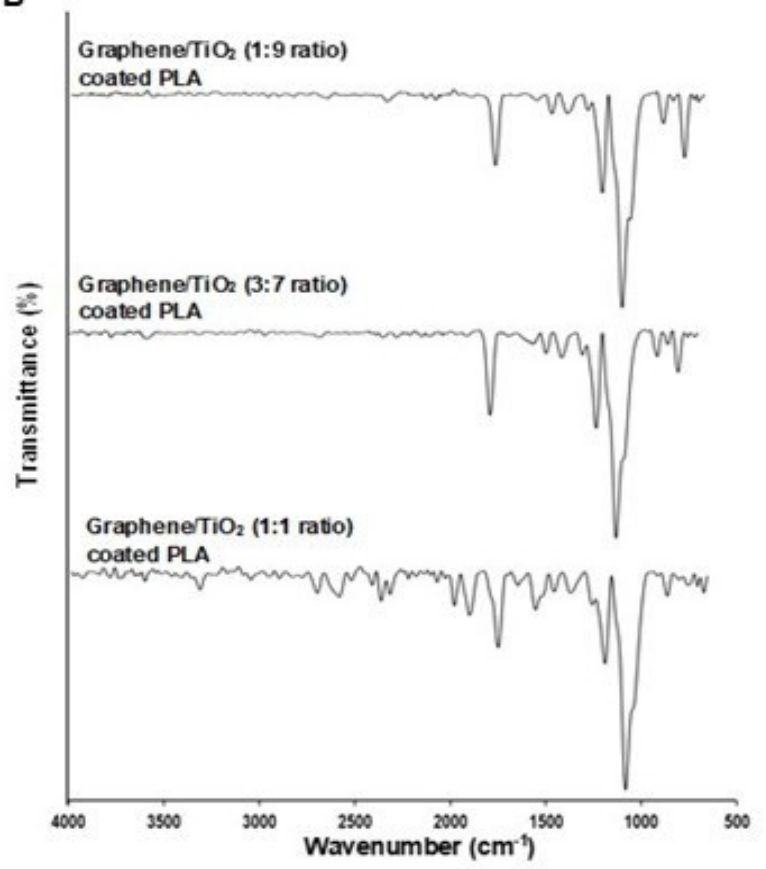

D

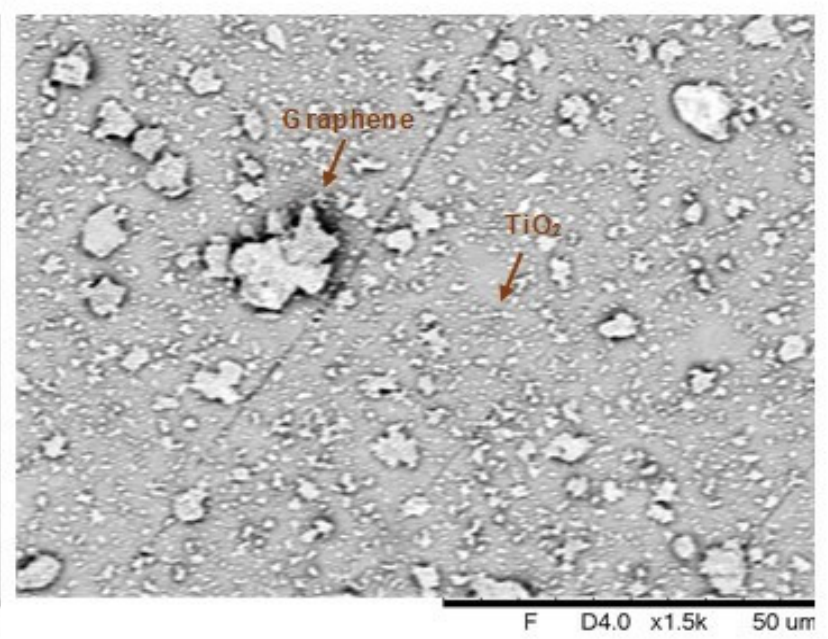

Figure 4. FTIR spectra of (A) the PLA film without coating, the graphene-coated film, and the $\mathrm{TiO}_{2}$ coated film, and $(\mathbf{B})$ the graphene $/ \mathrm{TiO}_{2}$-coated film. SEM images of $(\mathbf{C})$ the PLA film and (D) the graphene $/ \mathrm{TiO}_{2}$-coated PLA film.

\subsection{Durability Test}

The durability of the graphene/ $\mathrm{TiO}_{2}$-coated films are evaluated via the water immersion method, according to ASTM D870 [49]. The results from the water immersion test substantiated the excellent durability and stability of the graphene $/ \mathrm{TiO}_{2}$-coated film (Figure 6). The contact angles of the graphene $/ \mathrm{TiO}_{2}$-coated film decreased by approximately $2^{\circ}$ after being immersed in water for $5 \mathrm{~h}$. An additional period of water immersion, up to $24 \mathrm{~h}$, further decreased the contact angles by approximately $5^{\circ}$. Nonetheless, the contact angles of the three different ratios of the graphene $/ \mathrm{TiO}_{2}$-coated films remained above $150^{\circ}$ at the end of the water immersion test. This indicates that the immersion of graphene $/ \mathrm{TiO}_{2}$-coated film in water for a prolonged period does not result in a significant degradation of the coating. In the practical setting, it is not uncommon for medical devices to be in direct contact with body 
fluids for less than $8 \mathrm{~h}$. The result validates the effectiveness of the graphene $/ \mathrm{TiO}_{2}$-coated surface to be utilized for ample time. Hence, this study asserts the durability and robustness of the superhydrophobic graphene/ $\mathrm{TiO}_{2}$-coated PLA film and substantiate it to remain functional in the long run.

A

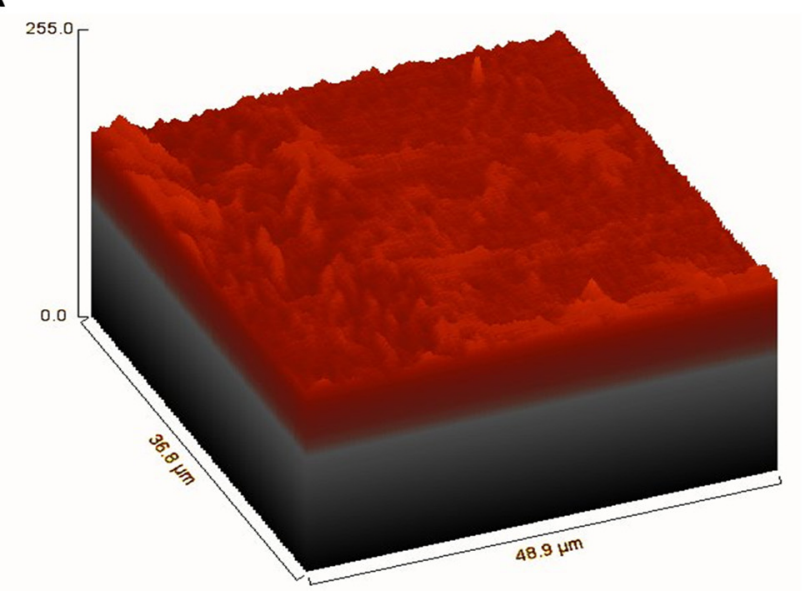

c

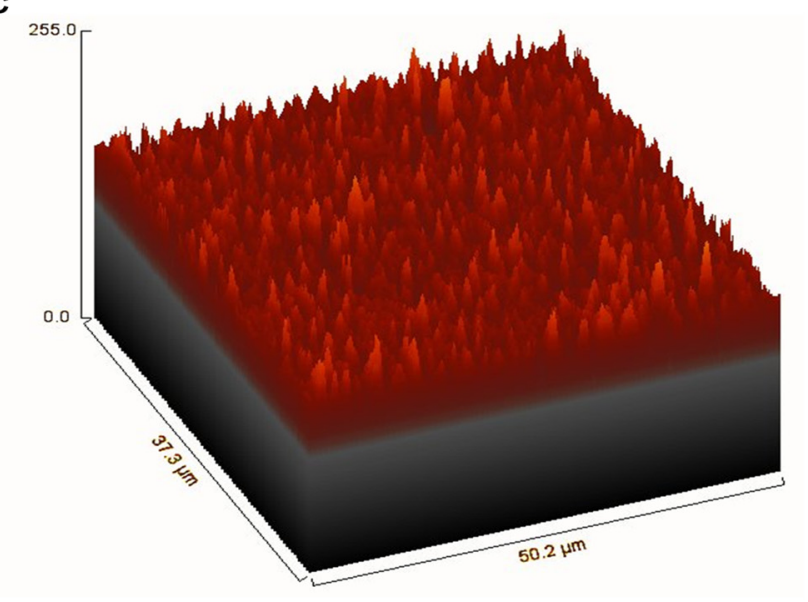

B

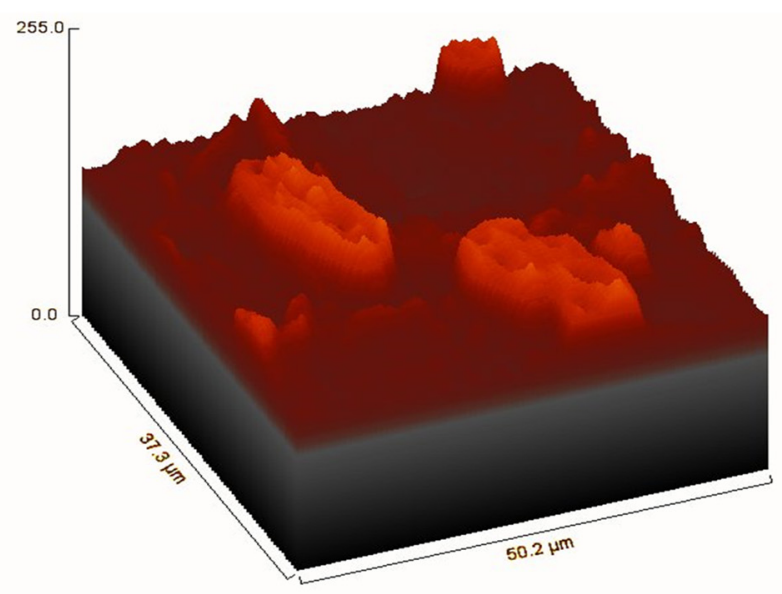

D

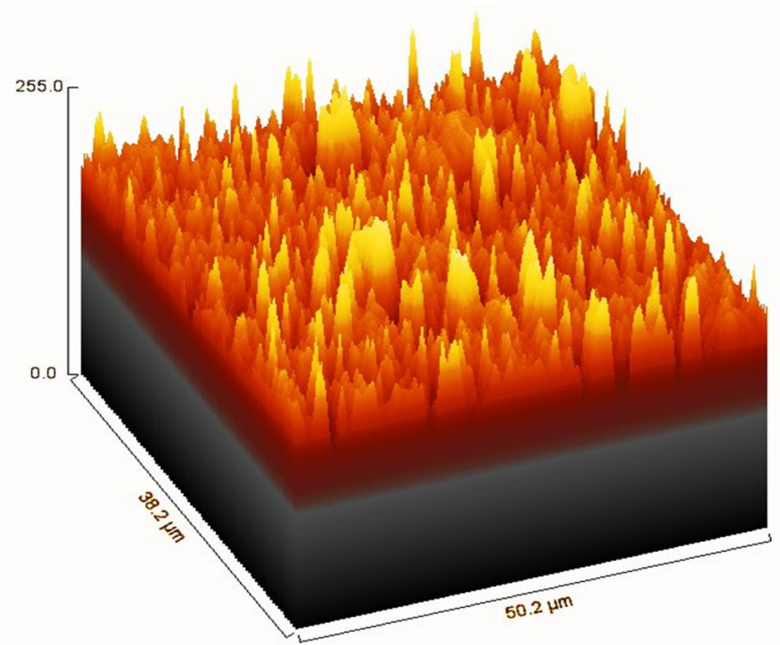

Figure 5. Three-dimensional representation of SEM images of (A) the non-coated PLA film, (B) the graphene-coated film, (C) the $\mathrm{TiO}_{2}$-coated film, and (D) the graphene/ $\mathrm{TiO}_{2}$-coated film.

The PLA films demonstrated superhydrophobic properties upon modification with the graphene $/ \mathrm{TiO}_{2}$ nanoparticles composite. This study reports the effectiveness of the graphene $/ \mathrm{TiO}_{2}$ nanoparticles for fabricating the superhydrophobic surface. The waterrepelling effect exhibited by the graphene $/ \mathrm{TiO}_{2}$ coating shows a promising antifouling and self-cleaning effect. The strategy herein is proposed as an ideal manufacturing method for superhydrophobic surfaces that are suitable for employment in medical devices. Further investigation is required to study the antibacterial activity, as well as the cytocompatibility, of the graphene/ $\mathrm{TiO}_{2}$-coated PLA surface. Nonetheless, this study offers a simple, time-saving, and eco-friendly method of fabricating a durable superhydrophobic graphene $/ \mathrm{TiO}_{2}$-coated surface. 


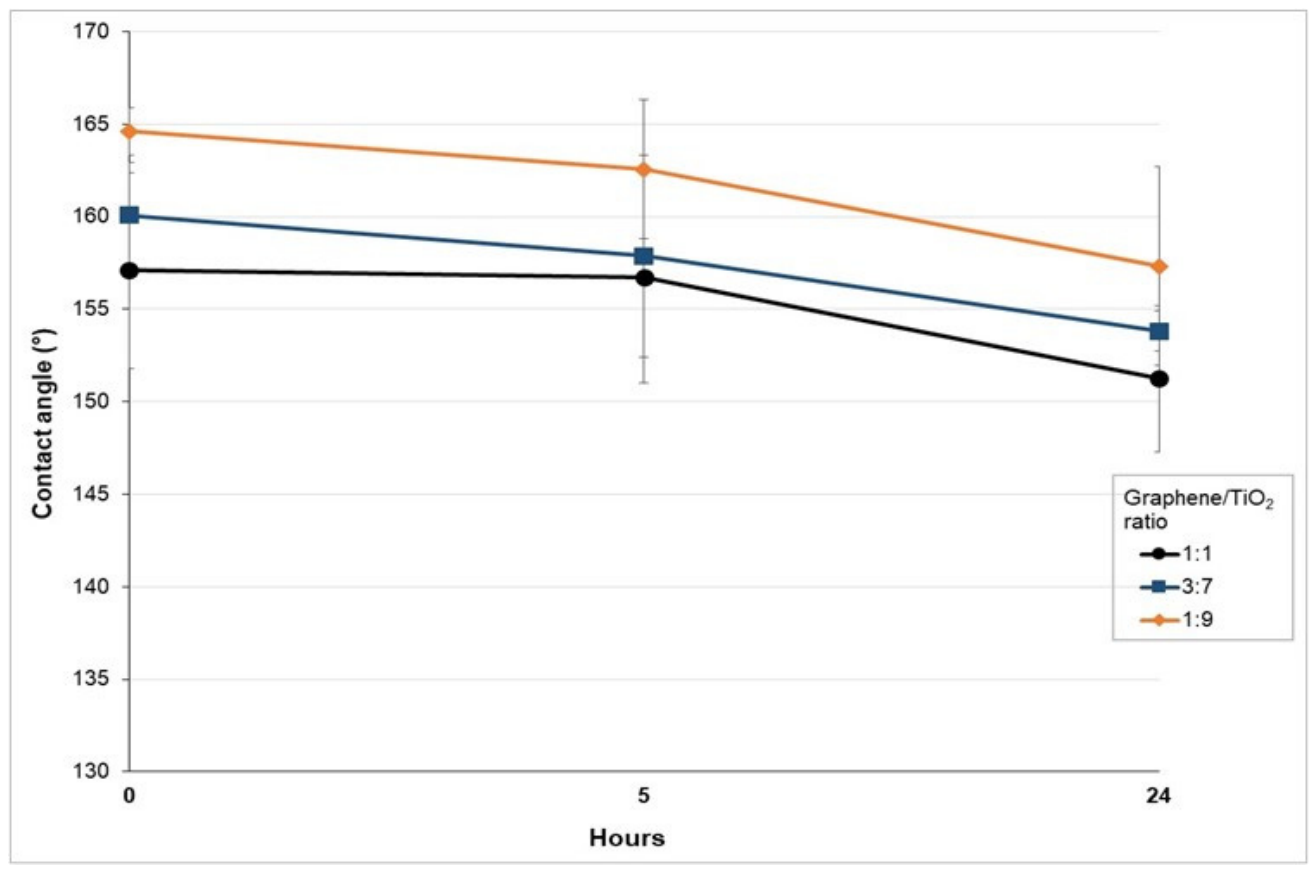

Figure 6. The durability of the superhydrophobic graphene $/ \mathrm{TiO}_{2}$-coated films via contact-angle measurement upon water immersion for $5 \mathrm{~h}$ and $24 \mathrm{~h}$.

\section{Conclusions}

A superhydrophobic surface was successfully fabricated by using graphene and $\mathrm{TiO}_{2}$ with a minimal concentration of $0.5 \% w / v$, via a simple dip-coating method. The graphene $/ \mathrm{TiO}_{2}$ coating showed superhydrophobic properties by exhibiting a high apparent contact angle. The apparent contact angle increased with the concentration of nanoparticles. Moreover, the coating of graphene and $\mathrm{TiO}_{2}$ hybrid exerted a synergistic effect by providing an enhanced surface roughness on the PLA surface. It is implied that the structured surface allowed for the entrapment of air pockets, which reduced the direct contact point between the water and graphene/ $/ \mathrm{TiO}_{2}$-coated surface. Therefore, the graphene $/ \mathrm{TiO}_{2}-$ coated PLA film demonstrated low wettability. Additionally, the ratio of graphene to $\mathrm{TiO}_{2}$ influenced the wettability of the coated surface. In brief, a superhydrophobic surface was achieved by using a minimal amount of graphene and $\mathrm{TiO}_{2}$ nanoparticles. In addition, the graphene $/ \mathrm{TiO}_{2}$ coating possesses significant durability and stability by demonstrating low degradation after overnight water immersion. This study shows a promising nanoparticles composite, prepared with graphene and $\mathrm{TiO}_{2}$, that is suitable for introduction into medical devices, where they can deploy their antifouling properties.

Author Contributions: Conceptualization and methodology, Y.Y.T.; investigation and data analysis, X.H.W.; writing — original draft preparation, X.H.W.; writing—review and editing, X.H.W. and Y.Y.T. All authors have read and agreed to the published version of the manuscript.

Funding: This research was funded by the Fundamental Research Grant Scheme (FRGS) from the Ministry of Higher Education of Malaysia (Project reference code: FRGS/1/2018/STG07/IMU/03/1).

Acknowledgments: X.H.W. and Y.Y.T. thank the School of Postgraduate Studies and the Institute for Research, Development, and Innovation (IRDI) of the International Medical University for the support given.

Conflicts of Interest: The authors declare no conflict of interest. 


\section{References}

1. Butt, H.-J.; Roisman, I.V.; Brinkmann, M.; Papadopoulos, P.; Vollmer, D.; Semprebon, C. Characterization of super liquid-repellent surfaces. Curr. Opin. Colloid Interface Sci. 2014, 19, 343-354. [CrossRef]

2. Hoshian, S.; Kankuri, E.; Ras, R.H.A.; Franssila, S.; Jokinen, V. Water and blood repellent flexible tubes. Sci. Rep. 2017, 7, 16019. [CrossRef] [PubMed]

3. Jeevahan, J.; Chandrasekaran, M.; Britto Joseph, G.; Durairaj, R.B.; Mageshwaran, G. Superhydrophobic surfaces: A review on fundamentals, applications, and challenges. J. Coat. Technol. Res. 2018, 15, 231-250. [CrossRef]

4. Roach, P.; Shirtcliffe, N.J.; Newton, M.I. Progess in superhydrophobic surface development. Soft Matter 2008, 4, 224. [CrossRef] [PubMed]

5. Verplanck, N.; Galopin, E.; Camart, J.C.; Thomy, V.; Coffinier, Y.; Boukherroub, R. Reversible electrowetting on superhydrophobic silicon nanowires. Nano Lett. 2007, 7, 813-817. [CrossRef]

6. Cassie, A.B.D.; Baxter, S. Wettability of porous surfaces. Trans. Faraday Soc. 1944, 40, 546-551. [CrossRef]

7. Yuan, Y.; Hays, M.P.; Hardwidge, P.R.; Kim, J. Surface characteristics influencing bacterial adhesion to polymeric substrates. RSC Adv. 2017, 7, 14254-14261. [CrossRef]

8. Zhang, X.; Wang, L.; Levänen, E. Superhydrophobic surfaces for the reduction of bacterial adhesion. RSC Adv. 2013, 3, 12003-12020. [CrossRef]

9. Maan, A.M.C.; Hofman, A.H.; de Vos, W.M.; Kamperman, M. Recent developments and practical feasibility of polymer-based antifouling coatings. Adv. Funct. Mater. 2020, 30, 2000936. [CrossRef]

10. Magin, C.M.; Cooper, S.P.; Brennan, A.B. Non-toxic antifouling strategies. Mater. Today 2010, 13, 36-44. [CrossRef]

11. Wu, X.H.; Liew, Y.K.; Mai, C.-W.; Then, Y.Y. Potential of superhydrophobic surface for blood-contacting medical devices. Int. J. Mol. Sci. 2021, 22, 3341. [CrossRef]

12. Bhushan, B.; Nosonovsky, M. The rose petal effect and the modes of superhydrophobicity. Philos. Trans. R. Soc. A Math. Phys. Eng. Sci. 2010, 368, 4713-4728. [CrossRef]

13. Hou, X.; Wang, X.; Zhu, Q.; Bao, J.; Mao, C.; Jiang, L.; Shen, J. Preparation of polypropylene superhydrophobic surface and its blood compatibility. Colloids Surf. B Biointerfaces 2010, 80, 247-250. [CrossRef] [PubMed]

14. Jaffer, I.H.; Weitz, J.I. The blood compatibility challenge. Part 1: Blood-contacting medical devices: The scope of the problem. Acta Biomater. 2019, 94, 2-10. [CrossRef]

15. Avrămescu, R.-E.; Ghica, M.V.; Dinu-Pîrvu, C.; Prisada, R.; Popa, L. Superhydrophobic natural and artificial surfaces-A structural approach. Materials 2018, 11, 866. [CrossRef] [PubMed]

16. Liu, X.; Yuan, L.; Li, D.; Tang, Z.; Wang, Y.; Chen, G.; Chen, H.; Brash, J.L. Blood compatible materials: State of the art. J. Mater. Chem. B 2014, 2, 5718-5738. [CrossRef]

17. Shamsudin, S.; Ahmad, M.K.; Aziz, A.N.; Fakhriah, R.; Mohamad, F.; Ahmad, N.; Nafarizal, N.; Soon, C.F.; Ameruddin, A.S.; Faridah, A.B.; et al. Hydrophobic rutile phase $\mathrm{TiO}_{2}$ nanostructure and its properties for self-cleaning application. AIP Conf. Proc. 2017, 1883, 20030.

18. Gao, Z.; Zhai, X.; Liu, F.; Zhang, M.; Zang, D.; Wang, C. Fabrication of $\mathrm{TiO}_{2} / \mathrm{EP}$ super-hydrophobic thin film on filter paper surface. Carbohydr. Polym. 2015, 128, 24-31. [CrossRef] [PubMed]

19. Luttrell, T.; Halpegamage, S.; Tao, J.; Kramer, A.; Sutter, E.; Batzill, M. Why is anatase a better photocatalyst than rutile?-Model studies on epitaxial $\mathrm{TiO}_{2}$ films. Sci. Rep. 2015, 4, 4043. [CrossRef]

20. Shateri-Khalilabad, M.; Yazdanshenas, M.E. Preparation of superhydrophobic electroconductive graphene-coated cotton cellulose. Cellulose 2013, 20, 963-972. [CrossRef]

21. Lorenzetti, M.; Dogša, I.; Stošicki, T.; Stopar, D.; Kalin, M.; Kobe, S.; Novak, S. The Influence of Surface Modification on Bacterial Adhesion to Titanium-Based Substrates. ACS Appl. Mater. Interfaces 2015, 7, 1644-1651. [CrossRef]

22. Wanag, A.; Rokicka, P.; Kusiak-Nejman, E.; Kapica-Kozar, J.; Wrobel, R.J.; Markowska-Szczupak, A.; Morawski, A.W. Antibacterial properties of $\mathrm{TiO}_{2}$ modified with reduced graphene oxide. Ecotoxicol. Environ. Saf. 2018, 147, 788-793. [CrossRef] [PubMed]

23. Xu, W.; Xie, W.; Huang, X.; Chen, X.; Huang, N.; Wang, X.; Liu, J. The graphene oxide and chitosan biopolymer loads $\mathrm{TiO}_{2}$ for antibacterial and preservative research. Food Chem. 2017, 221, 267-277. [CrossRef]

24. Nica, I.C.; Stan, M.S.; Popa, M.; Chifiriuc, M.C.; Pircalabioru, G.G.; Lazar, V.; Dumitrescu, I.; Diamandescu, L.; Feder, M.; Baibarac, M.; et al. Development and biocompatibility evaluation of photocatalytic $\mathrm{TiO}_{2} /$ reduced graphene oxide-based nanoparticles designed for self-cleaning purposes. Nanomaterials 2017, 7, 279. [CrossRef]

25. Nine, M.J.; Cole, M.A.; Johnson, L.; Tran, D.N.H.; Losic, D. Robust superhydrophobic graphene-based composite coatings with self-cleaning and corrosion barrier properties. ACS Appl. Mater. Interfaces 2015, 7, 28482-28493. [CrossRef] [PubMed]

26. Parra, C.; Dorta, F.; Jimenez, E.; Henríquez, R.; Ramírez, C.; Rojas, R.; Villalobos, P. A nanomolecular approach to decrease adhesion of biofouling-producing bacteria to graphene-coated material. J. Nanobiotechnol. 2015, 13, 82. [CrossRef] [PubMed]

27. Athanasiou, K.A.; Niederauer, G.G.; Agrawal, C.M. Sterilization, toxicity, biocompatibility and clinical applications of polylactic acid/polyglycolic acid copolymers. Biomaterials 1996, 17, 93-102. [CrossRef]

28. Benicewicz, B.C.; Hopper, P.K. Review: Polymers for absorbable surgical sutures-Part I. J. Bioact. Compat. Polym. 1990, 5, 453-472. [CrossRef] 
29. Relinque, J.J.; de León, A.S.; Hernández-Saz, J.; García-Romero, M.G.; Navas-Martos, F.J.; Morales-Cid, G.; Molina, S.I. Development of surface-coated Polylactic Acid/Polyhydroxyalkanoate (PLA/PHA) nanocomposites. Polymers 2019, 11, 400. [CrossRef] [PubMed]

30. Sharif, A.; Mondal, S.; Hoque, M.E. Polylactic acid (PLA)-based nanocomposites: Processing and properties. In Bio-Based Polymers and Nanocomposites; Sanyang, M.L., Jawaid, M., Eds.; Springer International Publishing: Cham, Switzerland, 2019 ; pp. $233-254$.

31. Jenkins, J.; Mantell, J.; Neal, C.; Gholinia, A.; Verkade, P.; Nobbs, A.H.; Su, B. Antibacterial effects of nanopillar surfaces are mediated by cell impedance, penetration and induction of oxidative stress. Nat. Commun. 2020, 11, 1626. [CrossRef]

32. Miwa, M.; Nakajima, A.; Fujishima, A.; Hashimoto, K.; Watanabe, T. Effects of the surface roughness on sliding angles of water droplets on superhydrophobic surfaces. Langmuir 2000, 16, 5754-5760. [CrossRef]

33. Geng, H.; Dai, J.; Li, J.; Di, Z.; Liu, X. Antibacterial ability and hemocompatibility of graphene functionalized germanium. Sci. Rep. 2016, 6, 37474. [CrossRef]

34. Han, W.; Wu, Z.; Li, Y.; Wang, Y. Graphene family nanomaterials (GFNs)—promising materials for antimicrobial coating and film: A review. Chem. Eng. J. 2019, 358, 1022-1037. [CrossRef]

35. Oh, H.G.; Lee, J.-Y.; Son, H.G.; Kim, D.H.; Park, S.-H.; Kim, C.M.; Jhee, K.-H.; Song, K.S. Antibacterial mechanisms of nanocrystalline diamond film and graphene sheet. Results Phys. 2019, 12, 2129-2135. [CrossRef]

36. Liu, J.; Ye, L.; Sun, Y.; Hu, M.; Chen, F.; Wegner, S.; Kappl, M.; Butt, H.-J. Elastic superhydrophobic and photocatalytic active films used as blood repellent dressing. Adv. Mater. 2020, 32, 1908008. [CrossRef] [PubMed]

37. Wei, X.; Yang, Z.; Tay, S.L.; Gao, W. Photocatalytic $\mathrm{TiO}_{2}$ nanoparticles enhanced polymer antimicrobial coating. Appl. Surf. Sci. 2014, 290, 274-279. [CrossRef]

38. Vijayanand, K.; Pattanayak, D.K.; Rama Mohan, T.R.; Banerjee, R. Interpreting blood-biomaterial interactions from surface free energy and work of adhesion. Trends Biomater. Artif. Organs 2005, 18, 73-83.

39. Sutera, S.P. Flow-induced trauma to blood cells. Circ. Res. 1977, 41, 2-8. [CrossRef] [PubMed]

40. Srinivasan, S.; Kleingartner, J.A.; Gilbert, J.B.; Cohen, R.E.; Milne, A.J.B.; McKinley, G.H. Sustainable drag reduction in turbulent Taylor-Couette flows by depositing sprayable superhydrophobic surfaces. Phys. Rev. Lett. 2015, 114, 14501. [CrossRef]

41. Yousefi, S.Z.; Tabatabaei-Panah, P.S.; Seyfi, J. Emphasizing the role of surface chemistry on hydrophobicity and cell adhesion behavior of polydimethylsiloxane/TiO2 nanocomposite films. Colloids Surf. B Biointerfaces 2018, 167, 492-498. [CrossRef]

42. Karapanagiotis, I.; Grosu, D.; Aslanidou, D.; Aifantis, K.E. Facile method to prepare superhydrophobic and water repellent cellulosic paper. J. Nanomater. 2015, 2015, 219013. [CrossRef]

43. Basu, B.J.; Dinesh Kumar, V. Fabrication of superhydrophobic nanocomposite coatings using polytetrafluoroethylene and silica nanoparticles. ISRN Nanotechnol. 2011, 2011, 803910. [CrossRef]

44. Mofokeng, J.P.; Luyt, A.S.; Tábi, T.; Kovács, J. Comparison of injection moulded, natural fibre-reinforced composites with PP and PLA as matrices. J. Thermoplast. Compos. Mater. 2012, 25, 927-948. [CrossRef]

45. Choksi, N.; Desai, H. Synthesis of biodegradable polylactic acid polymer By using lactic acid monomer. Int. J. Appl. Chem. 2017, 13, 377-384.

46. Bello, R.H.; Coelho, L.A.F.; Becker, D. Role of chemical funcionalization of carbon nanoparticles in epoxy matrices. J. Compos. Mater. 2017, 52, 449-464. [CrossRef]

47. Arriagada, P.; Palza, H.; Palma, P.; Flores, M.; Caviedes, P. Poly(lactic acid) composites based on graphene oxide particles with antibacterial behavior enhanced by electrical stimulus and biocompatibility. J. Biomed. Mater. Res. A 2018, 106, 1051-1060. [CrossRef] [PubMed]

48. Ba-Abbad, M.M.; Kadhum, A.A.H.; Mohamad, A.B.; Takriff, M.S.; Sopian, K. Synthesis and catalytic activity of TiO2 nanoparticles for photochemical oxidation of concentrated chlorophenols under direct solar radiation. Int. J. Electrochem. Sci. 2012, 7, 4871-4888.

49. ASTM International. Practice for Testing Water Resistance of Coatings Using Water Immersion; ASTM Standard D870; ASTM International: West Conshohocken, PA, USA, 2015. 